Bol. Acad. peru. leng. 54. 2012 (195-215)

\title{
LÉXICO UTILIZADO EN CONVERSACIONES IRÓNICAS
}

\section{LEXIQUE UTILISÉ AUX CONVERSATIONS IRONIQUES}

\section{THE LEXICON USED IN IRONIC CONVERSATIONS}

\author{
Teresa Ramos Quispe \\ Universidad San Agustín de Arequipa \\ Sociedad de Estudios Léxicos
}

\section{Resumen:}

Este trabajo analiza y explica de manera cualitativa la ironía verbal en conversaciones reales, tal como se desarrollan, tomando en consideración el contexto. Además, se ha diferenciado entre lo humorístico y lo crítico, ya que la ironía no solo sirve para criticar u ofender, sino para crear complicidad entre los interlocutores. Examinar el empleo del léxico ha sido clave para esta investigación, ya que en las conversaciones se han encontrado figuras literarias cargadas de ironía crítica que han sido usadas como atenuadores para eximir de responsabilidades al hablante; además, el oyente ha tenido que interpretar los enunciados adecuadamente para discernir el sentido pertinente.

\section{Résumé:}

Ce travail analyse et explique de façon qualitative l'ironie verbale dans les conversations réelles, tel qu'ils se développent, en prenant en considération le contexte. De plus, on a distingué entre l'humour et la critique, puisque l'ironie ne sert seulement à critiquer ou offenser, mais pour créer une complicité entre les interlocuteurs. Examiner 
l'emploi du lexique a été fondamental pour cette recherche, étant donné que dans les conversations on a trouvé des figures littéraires chargées d'ironie critique qui ont été utilisés comme attenueurs pour dispenser de responsabilités au locuteur; en plus l'auditeur ha dû interpréter les énoncés de façon adéquate pour discerner le sens pertinent.

\section{Abstract:}

This article analyses and explains in a qualitative way verbal irony in real conversations noting how they develop when a special context is taken into consideration. As well as this a difference is distinguished between humorous and critical, because irony is not only used to criticise and annoy, but also to establish a link of complicity among the speakers. The examination of the vocabulary used has been the key note of this investigation because in the conversations literary figures have been found charged with critical irony and that have been used as attenuators to relieve the responsabilities of the speaker. As well as this the hearer will have had to interpret the declarations correctly to discern the pertinent meaning.

Palabras clave: ironía verbal, irónica, humorística.

Mots clés: ironie verbale, ironique, humoristique.

Key words: verbal irony, ironic, humorous aspects.

Fecha de recepción:

Fecha de aceptación:
$18 / 06 / 2012$

$10 / 10 / 2012$ 


\section{PRAGMÁTICA Y ANÁLISIS DEL DISCURSO}

La lengua es parte del discurso y ofrece una serie de opciones, de entre las cuales hay que elegir en el momento de actuar discursivamente. Esta elección esta sujeta a parámetros contextuales que incluyen la situación, la intención del emisor y las características de los destinatarios, entre otros aspectos.

El análisis del discurso es describir el discurso como práctica social que implica una relación dialéctica entre un evento discursivo particular y la situación, la institución y la estructura social que lo configuran (Calsamiglia Blancafort 1999).

El discurso como práctica social es una forma de acción entre las personas, que se articula a partir del uso lingüístico contextualizado, ya sea oral o escrito, ya que estos son piezas textuales que se orientan hacia diferentes fines y que se dan en interdependencia con el contexto. El discurso se centra en el lenguaje "más allá de la oración".

Pueden asimilarse tres grandes parcelas de la pragmática:

a) Pragmática enunciativa. Centrada en el emisor. Sus unidades de análisis son: actos de habla, máximas conversacionales, deixis, presuposición, implicatura, negación e interjección.

b) Pragmática textual. Centrada en el enunciado y su organización interna. Coherencia, cohesión y conexidad.

c) Pragmática receptiva. Centrada en el receptor y en el uso del lenguaje en situaciones reales de interacción (Gallardo Paúls 1998).

Desde la pragmática ha de hablarse no de reproducción, sino de representación del discurso, y ha de observarse el cómo se representan los sujetos, cómo se interpretan los enunciados y con qué fines se utiliza el discurso. 


\section{IRONÍA}

\section{Teorías pragmáticas}

\section{La ironía en la teoría de los actos de habla}

Austin había excluido de su estudio a la ironía y el lenguaje no literal, dado que eran considerados "usos de la lengua no serios o parasitarios", y porque dificultaban una comprensión correcta de su teoría. La existencia de los actos ilocutivos indirectos constituye un serio problema para la teoría de Searle ya que debilita uno de sus supuestos fundamentales: el de la existencia de una relación entre la forma gramatical y el acto ilocutivo.

Searle, principal divulgador de las teorías de los actos de habla, pone en contacto los modos de la metáfora y la ironía con los actos indirectos del lenguaje, en los que difiere lo que se dice y lo que se quiere comunicar. Pone ejemplos: en la enunciación literal, el locutor dice "S es P", y quiere decir "S es P"; aquí el sentido de la frase coincide con el sentido de la enunciación. En la enunciación irónica, el locutor quiere decir lo contrario de lo que dice: el locutor dice "S es $\mathrm{P}$ " y el sentido de la enunciación es "S es R", ya que para acceder al sentido de esta hay que pasar por el sentido de la frase y de ahí al sentido contrario del sentido de la frase.

Si bien es cierto que esta expresión no es un simple traslado de los juicios tradicionales sobre la ironía a términos distintos, el autor exagera al proponer una interpretación en la cual los principios de la conversación y las reglas generales que gobiernan los actos de habla son suficientes para proporcionar los principios fundamentales de la ironía. Por ejemplo:

$\mathrm{INT}_{6}(\mathrm{G})$ : Que denuncie al peluquero, ieso sí! Que denuncie al peluquero porque ese iese!

$\mathrm{INT}_{7}(\mathrm{G})$ : Pero ¿a qué peluquería iba? A Conan's Pet.

$\operatorname{INT}_{8}(\mathrm{E}): \mathrm{jJa}, \mathrm{ja}, \mathrm{ja}, \mathrm{ja}, \mathrm{ja} \ldots$ ! 
Este es un claro ejemplo de cómo este estudio no aporta las condiciones contextuales de esta oración irónica, destacando solamente que es inapropiada para la situación, ya que el nombre Conan's Pet es inadecuado en la oración, pero no explica en qué consiste su impropiedad. No toma en consideración que lo que realmente determina a la ironía es la burla, el carácter intencionalmente irónico del emisor, ya que este es insincero de manera transparente.

\section{La ironía desde la teoría de la conversación de Grice}

Grice (1975) dio a conocer sus máximas de conversación:

Máxima de cantidad:

1. Hay que hacer la contribución tan informativa como sea preciso.

2. No hay que hacer la expresión más informativa de lo necesario.

Máxima de cualidad:

1. No hay que decir lo que se crea falso.

2. No hay que decir aquello para lo que se carece de evidencia apropiada.

Máxima de relación:

1. El mensaje ha de tener relación con el discurso.

Máxima de modo:

1. Hay que evitar la oscuridad de la expresión.

2. Hay que evitar la ambigüedad.

3. Hay que ser breve.

4. Hay que ser ordenado. (Citado en Torres 1999).

Grice presentó una teoría de la conversación, de carácter inferencial, a partir del concepto de implicatura, y, en cuanto a la ironía, basa su explicación en las nociones de implicatura conversacional y convencional; traslada el fenómeno de la ironía del campo de la semántica al ámbito de la pragmática (Torres 1999). 
En esta teoría propone que la ironía implica conversacionalmente lo contrario de lo que se dice, de esta manera reconvierte la noción tradicional de significado figurado en términos de implicatura conversacional, que se manifiesta veladamente en la comunicación irónica.

\section{La ironía en la teoría de la manifestación implícita}

Utsumi (2000), propone una nueva explicación que se apoya en los siguientes puntos:

a) La ironía verbal supone un marco situacional propio que se describe en términos de entorno irónico. Este consiste en la perspectiva del hablante, en la incongruencia entre lo que se espera y la realidad y en una actitud negativa del hablante hacia su incongruencia.

b) La ironía verbal es una expresión verbal que implícitamente manifiesta un entorno irónico.

c) La ironía verbal se distingue de la ironía tomando en consideración la condición del entorno irónico y de la manifestación implícita.

Esta teoría predice dos hechos acerca del tiempo de comprensión de la ironía:

a) Las ironías más prototípicas se perciben como más irónicas y se procesan más rápido.

b) Las ironías que se producen en una situación que se identifica con facilidad como entorno irónico se procesan más rápido.

\section{La ironía verbal}

La ironía verbal es la relación entre los signos y sus contextos. Desafía a la imaginación, y su descubrimiento por parte del receptor producirá en este el placer del éxito conseguido por su ingenio, ya que estará más cargada de una oscuridad estimulante para el receptor.

La ironía verbal como fenómeno pragmático refleja en la comunicación una actitud crítica o humorística del emisor que debe ser 
interpretada mediante la selección del contexto adecuado por el receptor. Este fenómeno paradigmático del lenguaje no literal constituye un hecho idiosincrásico del uso de la lengua como realización (fuerza ilocutiva), como intención, como uso interpretativo o argumentativo. Estas nuevas perspectivas ofrecen una explicación alternativa que se aleja de las descripciones retóricas o semánticas.

\section{TIPOS DE IRONÍA VERBAL}

\section{Ironía crítica}

Sirve para hacer crítica negativa de una forma indirecta, con aparente burla, pero con intención agresiva; se considera casi como un arma ofensiva y defensiva al mismo tiempo. A este tipo de ironía también se la califica como negativa, ya que pretende intimidar, ridiculizar o callar al interlocutor.

$\mathrm{INT}_{4}(\mathrm{G})$ : Eliancita no creía en nadie, el pitbull.

$\mathrm{INT}_{5}$ (E): Caja chica, nomás.

Aquí, el tono es más severo y violento, porque pasa de la crítica suave a la sátira o el sarcasmo. En este caso el sarcasmo y el reírse de alguien pueden proporcionar solidaridad entre aquellos que se ríen. El sarcasmo es una variante de la ironía, caracterizada por la intención cruel, hostil o maliciosa que expresa. Esta estrategia conversacional tiene la intención de dominar; pero en otro contexto, o en boca de otro hablante, puede suponer la intención de establecer una conexión. Esta dominación se crea en la interacción.

Este tipo de crítica refleja un juicio hostil o despectivo o un sentimiento de indignación o desprecio; se podría decir que su carácter es negativo. Los que hacen comentarios sobre una tercera persona se burlan de esta; pero claro que esto constituye un suceso que surge espontánea e improvisadamente.

\section{Ironía humorística}

Este tipo de ironía se produce para crear un juego de complicidades, reactivando el acuerdo sobre los valores o conocimientos compartidos 
por los interlocutores. El efecto de esta comunicación son la risa o la sonrisa.

$\mathrm{INT}_{5}$ (E): El hombre se parece a Mister Been, iCachetón! $\mathrm{INT}_{6}(\mathrm{G})$ : i $A y$ !, noooo, es la ministra, no seas malo.

Como vemos, en el ejemplo se plantea un juego de sentidos, en el que se busca la solidaridad y la complicidad del receptor. El efecto producido es la ruptura de las expectativas del receptor, cuyo desconcierto lo obliga a llevar a cabo un proceso de esclarecimiento de la intención para descubrir el verdadero sentido del mensaje.

El uso lúdico no es un uso especial del lenguaje limitado a la creación poética y literaria, sino que se incluye normalmente en el transcurso de la comunicación cotidiana para colaborar con las intenciones comunicativas del hablante. Estos aspectos no significan una desviación de la norma que rompe los principios comunicativos, sino que muestra una creatividad lingüística que consigue una efectividad comunicativa que el uso literal del lenguaje no habría podido provocar. Lo que les confiere el significado lúdico es el uso en la comunicación, como resultado de la actitud lúdica del emisor.

\section{IRONÍA VERBAL CON RELACIÓN A OTRAS FIGURAS Y PALABRAS EN EL DISCURSO}

\section{La metáfora}

Esta figura por la cual se designa una realidad (es decir, se asignan significados que no corresponden a las realidades referidas), ha sido objeto de estudio desde las más diversas perspectivas: desde la retórica, la estilística, la poética e incluso desde la filosofía del lenguaje.

Para Graciela Reyes, “(...) la metáfora es un exponente de carácter implícito de la comunicación humana ya que, esencialmente, toda o parte de la información necesaria para su comprensión debe ser recobrada por el oyente a partir de datos del contexto, especialmente nuestro conocimiento del mundo" (Reyes 2000: 149). Es decir, que en la interpretación de 
la metáfora hay que tomar en cuenta el conocimiento cultural de los interlocutores, el momento en el que se produce, el contexto y su relación.

La pragmática se ha ocupado de los rasgos lingüísticos de las metáforas, y de las condiciones de empleo que supone utilizarlas en contextos específicos. Este enfoque no solo tiene en cuenta los contextos sino los procesos de interpretación. La metáfora puede estar más convencionalizada que la ironía verbal, ya que se halla supeditada a los contextos de uso.

\section{Metonimia}

Figura que designa realidades por asociación de contigüidad, es decir, representa o conceptualiza metafóricamente algo en términos de otra cosa con la que guarda cierta relación: causa-efecto, continente-contenido, el signo por la causa significada, lo concreto por lo abstracto.

La metonimia permite expresar de una manera más simple; no busca producir un efecto comunicativo especial, sino solo la economía de producción. Es exclusiva de la emoción, pero interviene relativamente poco en su conceptualización. La diferencia entre la metáfora y la metonimia es que esta última opera dentro de los confines de un único dominio, es decir, asocia dos entidades conceptualmente contiguas pertenecientes al mismo dominio. Por ejemplo:

$\mathrm{INT}_{3}(\mathrm{G})$ : Luchito, Luchito Castañeda Lossio

$\mathrm{INT}_{4}^{3}(\mathrm{E}):$ iCasaca!

Como vemos aquí, la metonimia es la palabra "casaca" por asociación, ya que se está relacionando una casaca con una persona y se hace en son de burla. La finalidad es causar gracia, ya que el candidato y alcalde en ese momento se ponía mucho dicha prenda y sin darse cuenta hizo que esta se volviera un símbolo.

\section{Eufemismos}

Son las manifestaciones suaves y decorosas o de ideas cuya recta y franca expresión serían vulgares o tal vez mal sonantes. Los términos con un uso 
eufemístico en una situación pragmática determinada vienen a sustituir otras palabras que resultan incómodas o crudas, con el objeto de suavizarlas. Su matiz depende de múltiples circunstancias culturales y sociales.

El eufemismo es una expresión que sirve para disfrazar, para evitar una palabra socialmente chocante o marcada por un tabú. El disfrazar usualmente consiste en deformar a las palabras.

Dentro de tales circunstancias encontramos a los medios de comunicación. El que estamos analizando cumple su función: emplea estos términos dejando al arbitrio del oyente el modo de catalogarlo, de allí que constituya un fenómeno inestable y flexible.

\section{Juegos de palabras}

Son un procedimiento de corte verbal que consiste en el aprovechamiento de las propiedades combinatorias de los significantes, para obtener un intercambio de significados o de secuencias fonéticas insólitas y difíciles. Estas palabras guardan relación en su estructura fonética con otras que significan distintas realidades, lo que dependerá mucho del contexto de enunciación que ha de poner de manifiesto las propiedades de cohesión y coherencia para su correcta interpretación, claro está, considerando las reglas de combinación establecidas por el sistema.

\section{Interjecciones}

Una interjección es una palabra intercalada de emoción o sentimiento, convencionalizada hasta cierto grado. También es considerada como una palabra o grupo de palabras que no forman parte de la oración y que se destacan de esta por pausas y por una entonación diferente. Se escribe entre signos de admiración (i!).

Las interjecciones son rasgos lingüísticos que se dan habitualmente en el habla; poseen escaso contenido léxico, pero un gran valor funcional.

\section{Prolongadores}

Son signos vocálicos no verbales, también considerados "Típicos turnos de oyente que solo se explican por referencia a turnos de otro 
hablante" (Gallardo Paúls 1998: 33). Su papel es avisar al hablante que la repartición de papeles participativos se mantiene igual, es decir, que puede continuar hablando porque se le hace caso. Más o menos típicos son $<$ mmm, yaaa $>$; la mirada también.

\section{Corpus}

Está constituido por conversaciones del programa radial Caídos del Catre, de la emisora Studio 92, durante los meses de julio, agosto y septiembre del año 2006.

Criterios:

a) Fluidez en las conversaciones

b) Conversaciones espontáneas

c) Comentarios políticos

Datos del programa radial:

El programa radial Caídos del Catre de Studio 92 se emite en el horario de siete a diez de la mañana.

Datos de los locutores:

Locutor: Carlos Galdós.

En las transcripciones está identificado con la letra G.

Colocutor: Erick.

Identificado con la letra E.

\section{Técnicas}

Grabación

La observación documental

\section{Instrumentos}

Transcripción ortográfica

Cuestionario 


\section{TABLA 1}

\section{Referencias:}

Programa: Caídos del Catre

Locutor: Carlos Galdós

Colocutor: Erik

Sujeto de quien se habla: Luis Castañeda Lossio, en ese momento, candidato y alcalde de la municipalidad de Lima.

\section{Resumen:}

En los comentarios se alude al ex alcalde Luis Castañeda Lossio como Casaca. Este es el sobrenombre que los locutores le pusieron a Castañeda, ya que en su campaña electoral siempre se le vio usando una casaca color crema.

\section{TRANSCRIPCIÓN ORTOGRÁFICA}

\section{CONVERSACIÓN 1 - 01/07/2006}

$\mathrm{INT}_{1}(\mathrm{G})$ : Alcalde y candidato... ¿o la reelección?

$\mathrm{INT}_{2}$ (E): iYa!, Luchito.

$\mathrm{INT}_{3}(\mathrm{G})$ : Luchito, Luchito Castañeda Lossio.

$\mathrm{INT}_{4}$ (E): iCasaca!

$\mathrm{INT}_{5}(\mathrm{G})$ : Casaquita color caquita.

$\mathrm{INT}_{6}(\mathrm{G}): \mathrm{iJa}, \mathrm{ja}, \mathrm{ja}, \mathrm{ja}$ !, color caca.

$\mathrm{INT}_{7}$ (E): Le queda azul.

$\mathrm{INT}_{8}(\mathrm{G})$ : Hay gente que iay, no sé!, en realidad nunca pensé decir, pero en realidad es una casaca color caquita que se pone, feíta, ¿no? Pero es color caquita.

$\mathrm{INT}_{9}(\mathrm{E})$ : iClaro!

$\operatorname{INT}_{10}(\mathrm{G})$ : Es como que yo, yo le diría: “iOye, te queda bien la caca! Te cae bien”. Hay gente a quien la caquita le cae bien. 
$\operatorname{INT}_{11}(\mathrm{G})$ : Él es uno de esos seres humanos a los que ese color le queda bien.

$\mathrm{INT}_{12}(\mathrm{G})$ : El brother sigue encabezando.

\section{ANÁLISIS PRAGMÁTICO}

\section{EXPRESIÓN}

1. iYa!, Luchito.

Uso interjectivo: iYa!

\section{IMPLICATURA CONVERSACIONAL}

a) El hablante se siente asombrado y no puede dar crédito a la situación.

b) Trata de decir "no vayas tan rápido, ni abarques tanto".

\section{EXPRESIÓN}

2. iCasaca!

Uso interjectivo y metonímico: en su totalidad.

\section{IMPLICATURA CONVERSACIONAL}

a) Se refiere al alcalde y candidato dando énfasis en su vestimenta, exactamente en la casaca, por ello el uso de la interjección.

b) Usa la metonimia para ponerle a Luis Castañeda un sobrenombre, en el cual se usa la ironía y el humor. Debe quedar en claro que no es una crítica ni una agresión, sino que se enfoca la atención en algo peculiar que causa risa.

\section{EXPRESIÓN}

3. Casaquita color caquita.

Uso metonímico: en su totalidad. 


\section{IMPLICATURA CONVERSACIONAL}

a) Se está refiriendo al alcalde, pero agregándole otra característica que se refiere al color.

b) La expresión se hace graciosa, ya que asemeja la casaca con el color del excremento.

c) A pesar de que hay ironía, ya que el hablante se está burlando, se usa un atenuador logrando disminuir el efecto burlesco. Además, se proporciona una imagen positiva de quien se está hablando.

\section{EXPRESIÓN}

4. Hay gente que iay, no sé!, en realidad nunca pensé decir.

Uso eufemístico: en su totalidad.

\section{IMPLICATURA CONVERSACIONAL}

a) El hablante generaliza para no decir directamente que la vestimenta del candidato es fea y de esta manera no hacerse responsable de sus comentarios.

b) Él trata de convencer de que no quiere decir ni comentar sobre cómo se viste una persona, pero las circunstancias lo obligan.

\section{EXPRESIÓN}

5. iClaro!

Uso interjectivo: en su totalidad.

\section{IMPLICATURA CONVERSACIONAL}

a) Está de acuerdo por lo dicho anteriormente por su interlocutor y de esta manera acepta seguir el juego, para continuar las burlas.

b) Existe una complicidad entre ambos. Es como si le dijera sigamos. 


\section{EXPRESIÓN}

6. Hay gente a quien la caquita le cae bien.

\section{IMPLICATURA CONVERSACIONAL}

a) El hablante no quiere decir excremento, así que usa otra palabra con su diminutivo; esta hace que la ironía no sea $\tan$ fuerte ni tan agresiva.

b) El hablar de caca es repulsivo, y mucho peor si se utiliza como un apodo para una persona; sin embargo en este contexto no es una ofensa ya que se dice con cariño y se logra mitigar algo que a secas sería un agravio.

\section{EXPRESIÓN}

7. El brother sigue encabezando.

Uso metonímico: encabezando.

\section{IMPLICATURA CONVERSACIONAL}

a) Es metonímico porque relaciona la parte superior del cuerpo, la más importante, con estar primero en las encuestas o ser el preferido para ganar las elecciones. Está en primer lugar en las encuestas.

b) "Los ciudadanos prefieren a Luis Castañeda". Al decir esto, aclara todo el panorama: le tienen aprecio al candidato y de esta manera los comentarios no son críticos sino humorísticos.

\section{TABLA 9}

\section{Referencias:}

Programa: Caídos del Catre

Locutor: Carlos Galdós

Colocutor: Erik

Tema: Comparan la tecnología de la Policía Nacional del Perú con la de otros países de Europa. 


\section{Resumen:}

Los locutores se burlan de los policías de nuestro país, pues tienen que pagar de su sueldo para poder entrenarse a diferencia de lo que sucede en otros países, donde los encargados de sus Gobiernos los apoyan y les proporcionan una tecnología avanzada.

\section{TRANSCRIPCIÓN ORTOGRÁFICA}

\section{CONVERSACIÓN 9 - 02/08/2006}

$\mathrm{INT}_{1}(\mathrm{G})$ : iPucha!, y acá nosotros ¿qué? ¿Cómo es?, ¿no?, primer mundo; esta gente tiene billete pa' probar bombas nucleares y acá con las justas nomás los policías van a un descampado en el kilómetro cincuenta, a tirar balas, ¿no? $\mathrm{INT}_{2}$ (E): Y eso que cada bala les duele cuando disparan. $\mathrm{INT}_{3}(\mathrm{G})$ : Claro, porque se las cobran.

$\mathrm{INT}_{4}$ (E): iClaro! Tienen que poner de la suya, pues, hijito, imagínate.

INT $_{5}(\mathrm{G})$ : iPucha mare!

$\mathrm{INT}_{6}(\mathrm{G})$ : Acá, los norcoreanos prueban sus bombas nucleares; nosotros estamos probando nuestras molotov. $\mathrm{INT}_{7}(\mathrm{G})$ : 'Cha máquina, icómo queman llantas!

$\mathrm{INT}_{8}$ (E): iJa, ja, ja, ja, ja, ja!

$\mathrm{INT}_{9}$ (E): Como quemar llantas.

\section{ANÁLISIS PRAGMÁTICO}

\section{EXPRESIÓN}

1. iPucha!, y acá nosotros ¿qué? ¿Cómo es?, ¿no?

Uso eufemístico e interjectivo: ipucha! 


\section{IMPLICATURA CONVERSACIONAL}

a) Expresión que no arremete en este contexto ya que ha perdido el sentido ofensivo. Se refiere a prostituta.

b) El sentido es: "ahora qué hago", cuando se cometió un error.

\section{EXPRESIÓN}

2. ¿Qué? ¿Cómo es?, ¿no?, primer mundo.

Uso metafórico: primer mundo.

\section{IMPLICATURA CONVERSACIONAL}

a) Es metafórico porque se refiere a un lugar o país donde son más adelantados en tecnología, es decir, son primeros.

b) Conjunto de países donde hay mejores condiciones sociales, económicas, etc., con respecto de los países pobres.

\section{EXPRESIÓN}

3. Los policías van a un descampado en el kilómetro cincuenta, a tirar balas, ¿no?

Uso metafórico: a tirar balas.

\section{IMPLICATURA CONVERSACIONAL}

a) Es metafórico porque el hecho de lanzar significa movilizar un objeto de un punto a otro; en este caso se refiere a disparar balas. En esta expresión se empieza a utilizar la ironía crítica ya que el locutor se está mofando.

b) Es crítica porque el entrenamiento no solo consiste en disparar, sino en recibir adiestramiento tanto en seminarios como en cursos de acción. 


\section{EXPRESIÓN}

4. Y eso que cada bala les duele cuando disparan.

Uso metafórico: les duele.

\section{IMPLICATURA CONVERSACIONAL}

a) No se refieren a que los hayan golpeado, sino a que les incomoda, les molesta tener que pagar su armamento con su propio sueldo.

b) Los policías ganan poco, por ende tienen carencias en sus hogares, ya que les hace falta dinero para satisfacer sus necesidades básicas.

\section{EXPRESIÓN}

5. iClaro!

Uso interjectivo: en su totalidad.

\section{IMPLICATURA CONVERSACIONAL}

a) El locutor se refiere a que los representantes del Gobierno son los que deberían hacerse cargo de los gastos.

b) Esta expresión equivale a "por supuesto", dando énfasis.

\section{EXPRESIÓN}

6. Tienen que poner de la suya, pues, hijito.

Uso metafórico: hijito.

\section{IMPLICATURA CONVERSACIONAL}

a) Es metáfora puesto que el locutor tiene confianza con la persona a quien se dirige; no tiene ningún tipo de parentesco con él, sino una amistad. 


\section{EXPRESIÓN}

7. iPucha mare!

Uso eufemístico e interjectivo: en su totalidad.

\section{IMPLICATURA CONVERSACIONAL}

a) Expresión que no arremete ya que no está insultando ni agrediendo, a pesar de referirse a la palabra "puta madre".

b) Significa "¿ahora qué hago?", cuando se cometió un error.

\section{EXPRESIÓN}

8. 'Cha máquina, icómo queman llantas!

Uso eufemístico: ‘cha máquina.

\section{IMPLICATURA CONVERSACIONAL}

a) Expresión que no arremete, ya que ha perdido su significado ofensivo; se refiere a la palabra "puta madre".

b) Tiene las siguientes connotaciones: qué pena, qué cólera, cómo les hacen eso a los policías.

\section{CONCLUSIONES}

PRIMERA: En el análisis se ha demostrado que la ironía verbal es una actitud del hablante o emisor que se manifiesta en la comunicación, a través de diversos mecanismos explícitos e implícitos. Por ser un factor actitudinal, el oyente ha de interpretar adecuadamente para alcanzar el sentido pertinente de los enunciados.

SEGUNDA: En las conversaciones, hay un $80 \%$ de expresiones que están cargadas de ironía crítica, es decir, son burlescas, ofensivas y por 
ende poseen intención agresiva; y solo existe un $20 \%$ de expresiones cargadas de ironía humorística, es decir, sin ninguna intención de ataque, solo buscando la risa o sonrisa de los interlocutores.

TERCERA: El análisis da cuenta de que la ironía, siendo una figura literaria, usa otras figuras y palabras para materializar e intensificar la actitud irónica. La figura más usada es la metáfora, con un $31 \%$.

CUARTA: Existe complicidad entre los interlocutores cuando hacen los comentarios irónicos, y en la mayoría de los casos no hay compromiso porque se usan atenuadores o mitigadores. 


\section{BIBLIOGRAFÍA}

CALSAMIGLIA BLANCAFORT, Helena y Amparo TUSÓN VALLS

1999 Las cosas del decir: Manual de análisis del discurso. Barcelona: Ariel.

GALLARDO PAÚLS, Beatriz

1998 Comentarios de textos conversacionales: I. De la teoría al comentario. Madrid: ARCO.

REYES, Graciela, E. BAENA y E. URIOS

2000 Ejercicios de Pragmática. Madrid: ARCO.

TORRES SÁNCHEZ, María Ángeles

1999 Aproximación pragmática a la ironía verbal. Cádiz: Universidad de Cádiz.

UTSUMI, A.

2000

"Verbal irony as implicit display of ironic environment: distinguishing ironic utterances from non irony". En: Journal of Pragmatics, n. ${ }^{\circ} 32$, pp. 1777-1806.

\section{Correspondencia:}

\section{Teresa Ramos Quispe}

Licenciada en Literatura y Lingüística por la Universidad Nacional de San Agustín de Arequipa.

Correo electrónico: tecchhi@hotmail.com 